\title{
Book Review: Bodily Regimes: Italian Advertising under Fascism
}

By Astrid Van den Bossche

There seems to be no shortage of iconic Italian advertising. The origins of some strands and styles of these campaigns are, however, steeped in a history rarely acknowledged in the casual exhibition of these highly stylized posters, better known now for their aesthetic qualities than for the products they endorsed, or the society in which they originated. Italian advertising created between the 1920s and WWII was, on the one hand, subject to constraints and censorship imposed by the Fascist regime under Benito Mussolini, and on the other, representational of the Fascist ideology that characterized contemporaneous Italian culture. Not quite propaganda, but not far from it either, these ads allow for sophisticated understandings that lay bare endemic tensions and anxieties. Documenting a subset of these ads, Karen Pinkus demonstrates in Bodily Regimes: Italian Advertising under Fascism (1995) that the treatment of the body implied an Italian subject thoroughly imbued in Fascist ideology—gender, sexuality, health, the worker, and the productive cycle, all can be read as subject to Fascist values.

The first chapter, "The Body and the Market," wastes no time in setting the tone for the remainder of the book and introduces the author's understanding of the body's place in advertising and Fascism. Pinkus explains her conceptual use of iconography, a term borrowed from art history, to uncover the symbolic and implied content of mass media imagery, thus proposing that these images express something akin to "a political unconscious" (p. 5). The way the body is represented in advertising thus expresses more than just a desire to connect with the viewer and elicit identification with the promotional messages. Under Italian Fascism, Pinkus argues, this identification is exercised through a specific visual language that draws from the body cult of Fascist dictator Mussolini, thereby drawing deep connections between politics and advertising. 
What's more, that line was drawn to the market itself through the chocolate manufacturers' Perugina-Buitoni figurine craze, yet another example of the power of the body at the intersection of advertising and ideology: "the chocolate brokers had traded away the humanizing veneer of the little dolls for the reality of capital accumulation" (p.19). This collection of preparatory notes serves as Pinkus' springboard for the ensuing chapters.

In her second chapter, "Selling the Black Body: Advertising and the African Campaigns," Pinkus gets straight to the point: Rooted not only in racist but also Fascist discourse, the representation of the black body takes on connotations that today may no longer seem very deep but that would have made specific ideological statements to the contemporary Italian audience.

Paralleling Italy's colonialist endeavors and its concomitant domestic discourse, the black body as represented across the media reflects on (Fascist, male) whiteness and Italy's position vis-à-vis Africa and Europe. Marinetti's 1909 novel, Mafarka le futuriste, roman africain, highly criticized in Italy for its sexually explicit nature, offers one of the most notable examples of a racist discourse prefiguring Africa as a licentious, amoral, uncivilized wilderness to be conquered by military/sexual virility. Amplified with racist notions of Jewishness, the paradigm was wholly adopted and relied on in subsequent representations of the black body, abstracted into self-evidence through the highly geometric forms of Italian futurism (see Figure 1 for an example of this style). This characteristic visual style gains significant currency also in advertising imported goods, such as coffee, chocolate, and sugar, as well as in political propaganda and financial services. 
Pinkus distinguishes between five key icons and their specific significations: a) the Smiling Negress, a Somali beauty who is both the height of sensuality and the ultimate abject prostitute; b) the Asiatic Worker, the feudal laborer kept in line by Fascist ideology; c) the Silent Arab, a Libyan figure veiled and thus hidden from view; d) the Moretto, the Moor whose sexuality is feminized into innocuousness; and e) the Black Baby, whose need for rescue serves as yet another vehicle of Fascist paternalism.

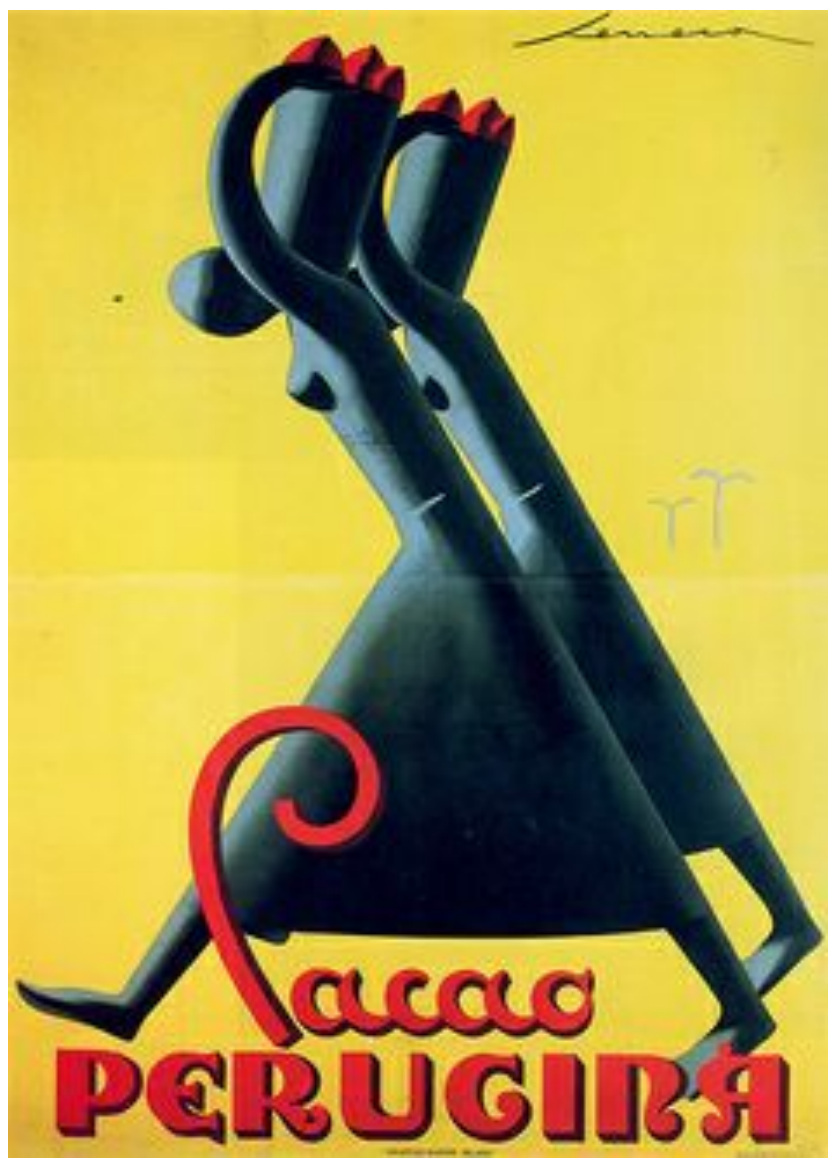

Figure 1 Perugina chocolate women by Seneca

Given that Fascist ideology tends to entrench issues of production and consumption in nationalist and paternalist concerns-as hinted at through some of the discussion on blackness-Pinkus unpacks the representation of the Fascist producer/consumer in her 
third chapter. A productive line of inquiry can be found in her discussion of the preFascist culture of artisanship and its subsequent romanticization into artistry. Yet taking the allegorical use of the body to a new level, her subsequent discussion devolves into a somewhat difficult, inaccessible, and rather unconvincing Freudian reading: The Fascist unconscious is portrayed as a regression to the anal stage of psychic development, to which constipation and defecation are real sense-making concerns. Pinkus's reading of advertisements as Oedipal dramas of alien destruction or anal control (see Figure 2), for example, remains obscure and does not quite capture how the ads would have resonated with their audiences.

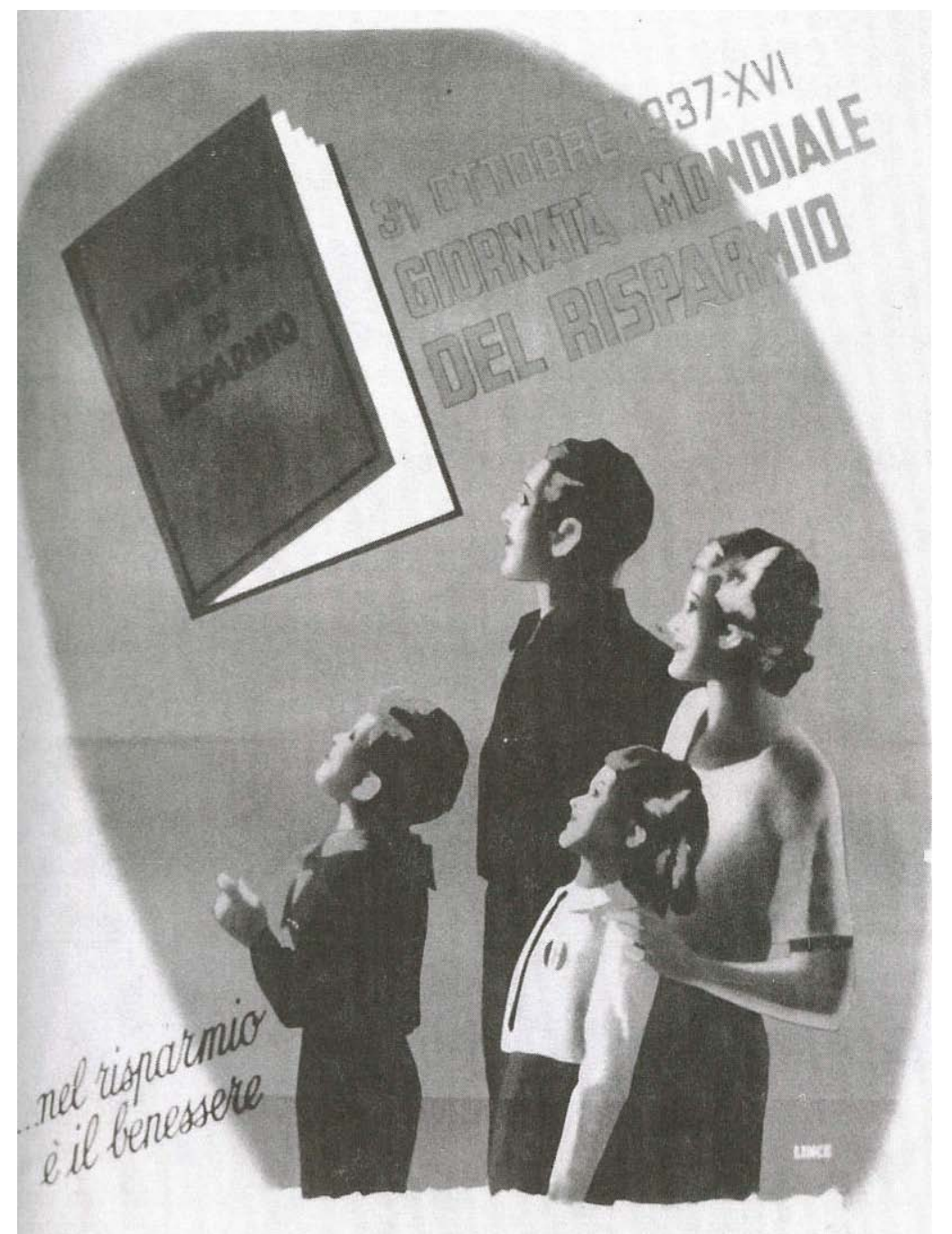

Figure 2 An (Oedipal) savings-day campaign, Salce Collection, in Pinkus 1995 
In "The Body and Its Armors," chapter four, Pinkus focuses on the gendered body —or as her argument goes, the de-gendered body-and ramifications into sexuality and Fascist identity. Once more bringing together an eclectic collection of advertisements, she examines in turn themes such as the "male armor" (exemplified by the raincoat, see Figure 3), the moral hygiene of the public bath, the duality of the radio, and the death/freedom tension in sports. The Fascist preoccupation with highly gendered spheres, and its emphasis on the woman's duty to reproduce, shines through the highly stylized and sometimes homo-eroticized bodies.

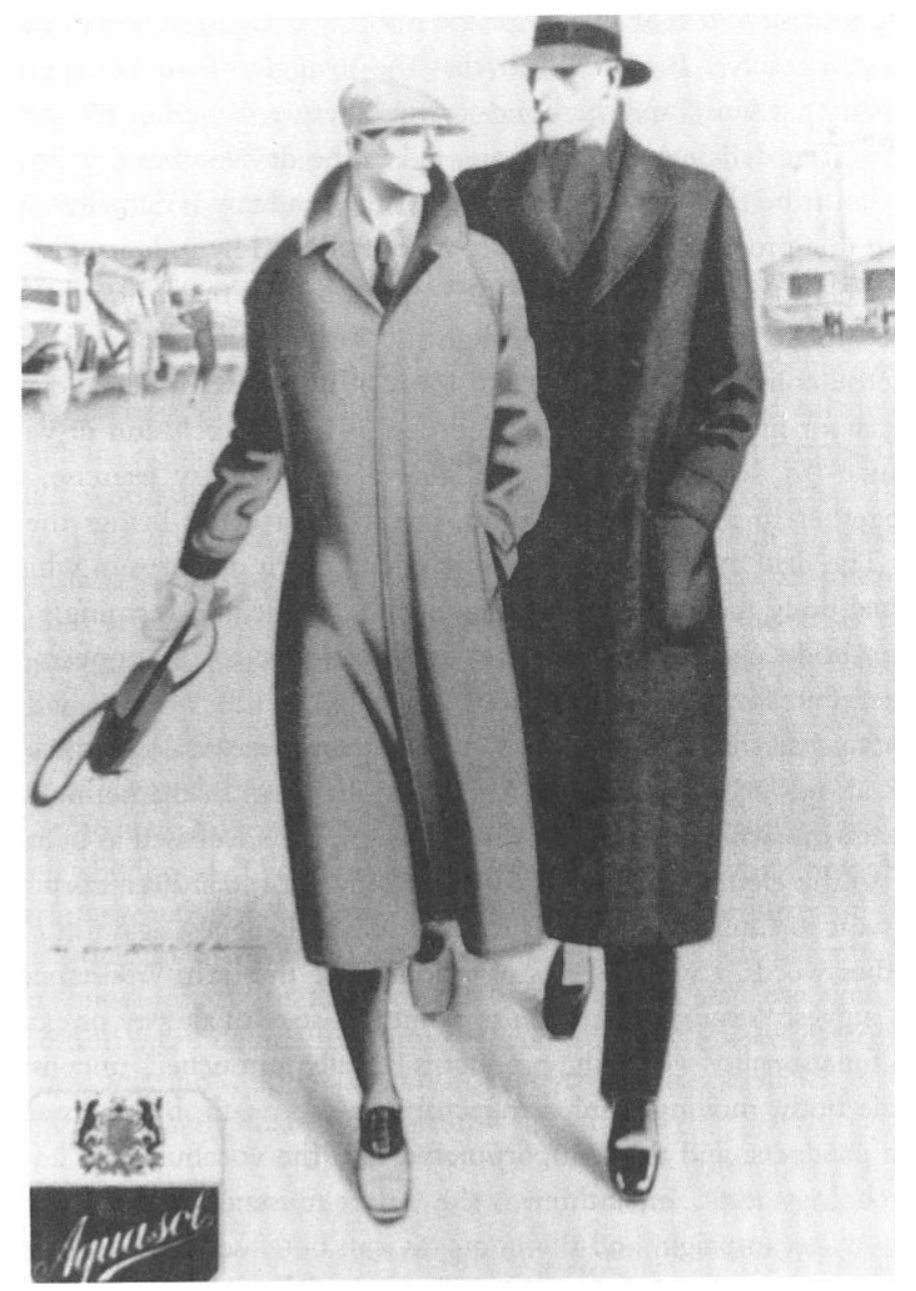


In her final and summarizing chapter, "The Body Disappears," Pinkus describes the Fascist disavowal of the body, by which she emphasizes that Fascist iconography does not outright negate bodily existence, but simultaneous affirms it and denies it by contorting its "naturalness" into Fascist ideals. Going into some depth about the popularization of rayon (see Figure 4), for example, Pinkus links revolutionary technologies, the tenuous gendering of labor, and consequent consumer behavior in this market to trace the societal anxieties reflected in how the body both features and disappears in the textile's ad campaigns. The discourse around smoking and "rays from the eye" further exhibit the double act of appearance and effacement linked to Fascist notions of how certain health aspects and technologies affect the self. Ultimately, Pinkus sees these images as exemplary of the ideological tensions that echo through advertising: "In living out a relation to fascism, the body both adapts to control and, at the same time, absents itself.... [D]isavowal serves as a convenient metaphor for a state in between the extremes of total embodiment and utter annihilation" (p. 238-43). 


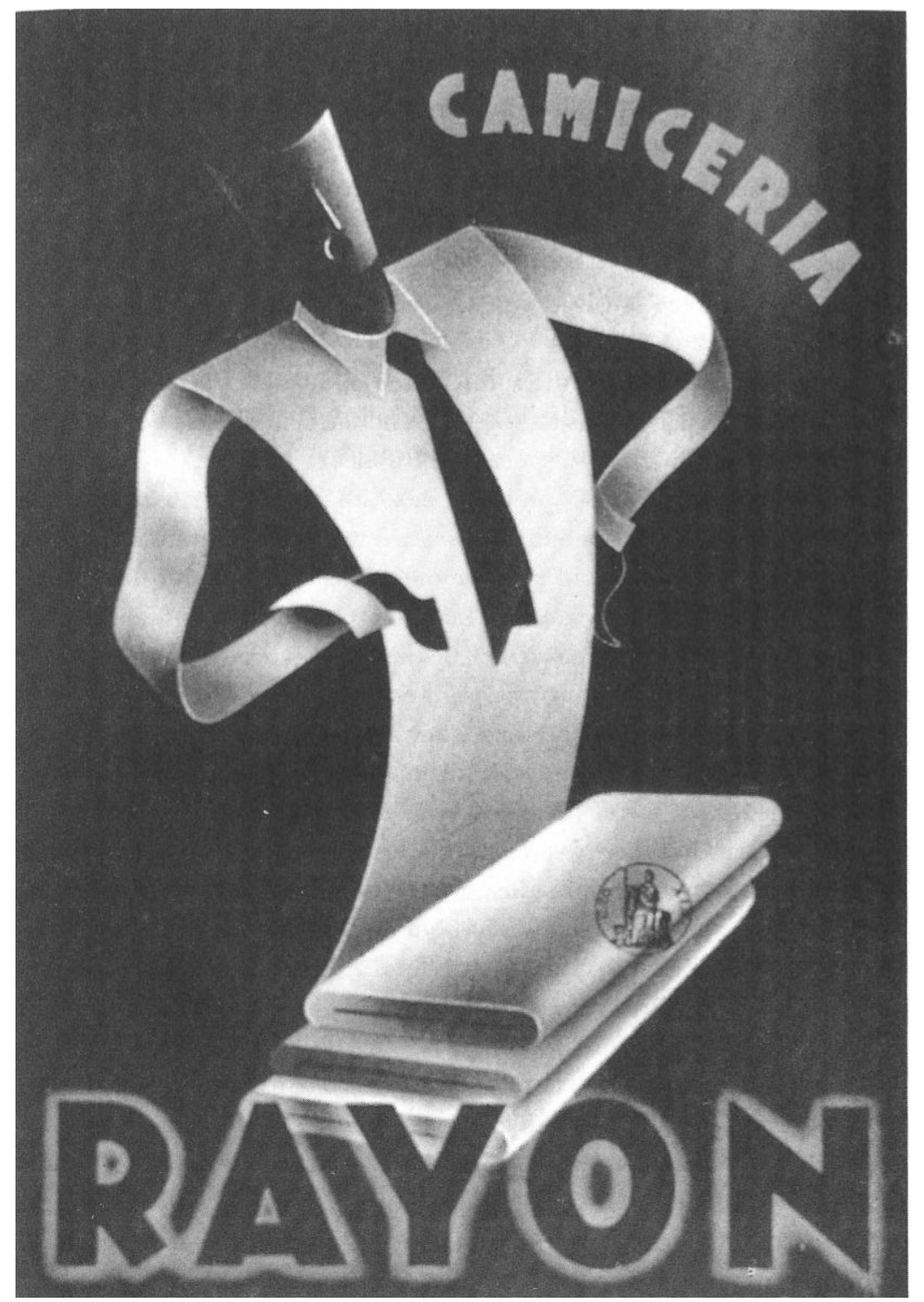

Figure 4 Cavadini Rayon man advertisement, Salce collection, Pinkus 1995

As a whole, Bodily Regimes is a potentially illuminating but tough-going read even for audiences familiar with the many psychoanalytic texts and thematic reaches on which Pinkus's arguments rely. The book reveals a very different approach to advertising scholarship: To build her argument, she reaches into, among others, the contexts of production, socioeconomic and political impetus, conversations with contemporaneous arts, and miscellanies of other texts. Such research has both its merits and its dangers. But mostly it illustrates that as a cultural phenomenon, there is great depth to be revealed in the deconstruction of successful advertising. As such, it is beneficial to 
become conversant in the insights these studies offer, despite their occasional lack of corroboration or generalizability. Pinkus' work thus sets the tone for a sophisticated understanding of advertising and society, suggesting that the success of an era's advertising machine is deeply entrenched in the shaping and the consumption of an ideology.

\section{Astrid Van den Bossche}

Astrid Van den Bossche is a doctoral student in Management Studies at Saïd Business School, University of Oxford. Under the supervision of Professor Linda Scott, her research spans across marketing history, consumer culture theory, and branding. Prior to beginning her studies at Saïd Business School, Astrid obtained a Master of Studies in Film Aesthetics at the University of Oxford. She then taught as an Alumni Tutor at her undergraduate college, University College Maastricht in The Netherlands, before completing a Master in Management at London Business School. Her particular interest in branding and marketing was awakened during her work experience as a brand strategist.

\section{Contact details}

Saïd Business School

Park End Street

Oxford, OX1 1HP, UK

E-mail: astrid.vandenbossche@sbs.ox.ac.uk 